\title{
CORRIGENDUM
}

\section{Minimal ureagenesis is necessary for survival in the murine model of hyperargininemia treated by AAV-based gene therapy}

C Hu, DS Tai, H Park, G Cantero, E Chan, M Yudkoff, SD Cederbaum and GS Lipshutz

Gene Therapy (2015) 22, 216; doi:10.1038/gt.2014.127

Correction to: Gene Therapy (2015) 22, 111-115; doi:10.1038/ gt.2014.106; published online 4 December 2014

Since the publication of this paper, the authors have realized that one of the author names was displayed incorrectly. G CanteroNieto should have appeared as G Cantero.
The corrected author list is shown here. The article has also been rectified and now carries the correct information.

The authors apologize for any inconvenience caused. 